Article

\title{
A Discursive Approach to Mediatisation: Corporate Technology Discourse and the Trope of Media Indispensability
}

\author{
Karin Fast \\ Department of Geography, Media and Communication, Karlstad University, 65188 Karlstad, Sweden; \\ E-Mail: karin.fast@kau.se
}

Submitted: 14 December 2017 | Accepted: 28 February 2018 | Published: 25 May 2018

\begin{abstract}
Hitherto, and mainly by way of ethnographic studies, mediatisation research has informed us regarding the relevance, influence, and role of media in various spheres of social life. Less is known, however, about how mediatisation is discursively constructed. The relevance of constructivist approaches to mediatisation has been explicated, e.g., by Krotz (2017), who calls for critical mediatisation studies that consider the economic interests of mediatisation stakeholders, including the ICT industry. Against this backdrop, this article scrutinizes what the alleged 'mobility revolution' entails according to some who would benefit most from such a revolution. More concretely, the article studies the discursive practices of three leading corporations in the mobile communications sector: IBM, Huawei, and Ericsson. Stimulated by critical mediatisation theory as well as related accounts of the (technology) discourse-reality relationship, the article asks: if mobile media changes 'everything' in life-whose lives are being changed? If mobile media are 'indispensable' to modern ways of living-what are they supposed to do? Ultimately, the article speaks to the theme of this thematic issue by interrogating how contemporary mobile technology discourse contributes to the (re-)production of social space. Findings suggest that mediatisation is constructed as the response to an internal human drive for connectivity and as an inexorable natural force. Three sub-discourses on mobile technology are identified: 'technologies of cosmos', 'technologies of self', and, ultimately, 'technologies of life'. Altogether, these sub-discourses disclose and reinforce the hegemonic nature of mediatisation by communicating the indispensability of mobile media in modern-notably, urban and privileged-lives. In addition to providing answers to the study's empirical questions, the article includes a discussion about the potential implications of existing discourse overlaps between ICT companies and mediatisation theorists, as well as a sketch for an agenda for the 'discursive turn' in mediatisation studies.
\end{abstract}

\section{Keywords}

discursive turn; media indispensability; mediatisation; mobile media; mobility revolution; technology discourse; Social Construction of Technology (SCOT); social space

\section{Issue}

This article is part of the issue "Rethinking Media and Social Space", edited by André Jansson and Johan Lindell (Karlstad University, Sweden).

(C) 2018 by the author; licensee Cogitatio (Lisbon, Portugal). This article is licensed under a Creative Commons Attribution 4.0 International License (CC BY).

\section{Introduction}

When the 'World Wide Web' started to mature, the 'information revolution' was celebrated by researchers, politicians, policy makers, and others. Today, a new kind of technologically driven revolution is said to emerge: the mobility revolution. Predictably, the revolutionary potentials of mobile media are particularly promoted by Information and Communication Technology (ICT) compa- nies. The multinational corporation Ericsson, for example, claims in their investors reports that mobile media have led us to 'the brink of an extraordinary revolution that will change our world forever' (Ericsson, 2017, p. 2). In a similar vein, Ericsson's competitor IBM states in one of their most recent booklets that 'Just as the Internet did before, mobile networks - and the devices that exploit them-are radically changing the way we interact with the world' (IBM, 2017, p. 1). Obviously, producers 
of communications technology have a stake in marketing their gadgets as desirable. This ambition is at the core of all advertising (Ewen, 2001). Beyond creating consumer demand for singular commodities, however, commercial corporations also have a stake in shaping public opinion on a larger scale. By presenting mobile media as tools of radical change, ICT companies ultimately construct such media as indispensable-as things necessary to lead a good life.

While heavily promoted by technology producers, the media indispensability trope is not exclusive to the ICT industry. Rather, the trope also occurs in media research and in mediatisation theory especially. Although there are still many suggestions as to how to define mediatisation (cf. Couldry \& Hepp, 2013; Ekström, Fornäs, Jansson, \& Jerslev, 2016; Hepp \& Couldry, 2016; Hjarvard, 2013; Krotz, 2009, 2017; Lundby, 2009), the notion of media indispensability has been suggested as key to the concept. Jansson (2014, 2015a, 2015b, 2018) argues that today 'we can see that media are generally, and to an increasing extent, perceived as indispensable to the interactions between individuals and groups' (Jansson, 2015a, p. 380, original emphasis). Notwithstanding other areas of potential dispute, then, mediatisation researchers and the ICT industry seem to unite in the recognition of media technologies as agents of social change. However, whereas the media indispensability trope appears in both corporate texts and mediatisation literature, there are some significant differences in term of how the alleged change is regarded.

Contrary to much ICT rhetoric, critical mediatisation studies tend to highlight the social costs of actual or perceived media dependence, including, for instance, anxieties associated with the dissolved boundaries between work and leisure (Fast \& Lindell, 2016), feelings of unease connected with mediated forms of selfrealization or 'recognition work' (Jansson, 2018, Chapter 4), or, more generally, perceptions of entanglement (Hjarvard, in press). Similar alternative discourses on media indispensability - and guidelines for how to deal with the down-sides of media dependence-also flourish in contemporary public debates. Symptomatically, Forbes magazine recently forecasted 'digital detox' as a dominant trend of 2018: 'It started happening ever so quietly in the fourth quarter of 2017. The digital detox. Now, watch for it to be a major trend in 2018. From your work life to your personal life, everyone is in search of the ultimate luxury: tech-free hours' (Goldston, 2018). Currently thus, competing narratives exist in relation to media indispensability. Aside from 'detox handbooks' offered by trend-sensitive journalists, workers' unions, parenting groups, health organisations, occupational health care units, and other civil organisations are presently contributing to public awareness around some of the more troublesome aspects of mediatisation.

Hitherto, and mainly by way of ethnographic studies, mediatisation research has informed us of the relevance, influence, and role of media in various spheres of social life, including, for example, close relationships (Klausen \& Møller, 2018), parenthood (Damkjaer, 2017), mobile livelihoods (Jansson, 2018; Polson, 2016), work life (Gregg, 2011), politics (Esser \& Strömbäck, 2014), and religion (Hjarvard, 2008). Less is known, however, about how mediatisation, or the idea of media as indispensable drivers of social change, is discursively constructed. Against this backdrop, this article identifies a need for a discursive turn in mediatisation research and so approaches the 'mobility revolution' from a discursive standpoint. The relevance of constructivist approaches to mediatisation has been explicated by Krotz (2017), who calls for critical mediatisation studies that consider the economic interests of mediatisation stakeholders, including the telecom industry. As a process accomplished by humans rather than a natural given, he argues, mediatisation must 'be reconstructed critically in order to find the points where the civil society was not asked' (Krotz, 2017, p. 114). While alternative interpretations of the social consequences of media indispensability (such as those mentioned above) are obviously gaining momentum in the public debate, Krotz's call for critical studies of mediatisation stakeholders is indeed sympathetic given the rampant financial and soft powers of ICT corporations (Nye, 2002).

This article responds to Krotz's and others' recent pleas for critical mediatisation studies (see also, e.g., Jansson, 2013, 2018), by asking what the alleged mobility revolution entails according to some of those who would benefit the most from such a revolution. More concretely, the article studies the discursive practices of three leading corporations in the mobile communications sector: American IBM, Chinese Huawei, and Swedish Ericsson. Stimulated by critical mediatisation theory as well as related accounts of the (technology) discourse-reality relationship (e.g. Berger \& Luckmann, 1966; Fisher, 2010a, 2010b; Marvin, 1988; Pinch \& Bijker, 1984; Schutz, 1967; Williams, 1974), the article asks: if mobile media changes 'everything' in life-whose lives are being changed? If mobile media are 'indispensable' to modern ways of living-what are they supposed to do? Ultimately, the article speaks to the theme of this thematic issue 'Media and Social Space: Analysing Mediation and Power' by interrogating how contemporary mobile technology discourse contributes to the (re-)production of social space.

In this article, the meaning of social space lies at the intersection of the Bourdieusian and Lefebvreian understandings of the concept. While the two understandings of social space can seem at odds with one another-not least given their differences in terms of weight given to place-they can be fruitfully brought together in analyses to point at the interrelationship between discourse and social power (see, e.g., Centner, 2008, for such an analysis, centred around the concept of 'spatial capital'). Bourdieu's $(1989,1998)$ social space is a space of positions defined in relation to one another, in which groups of agents who share similar circumstances (habi- 
tus/capital) can form social classes. Lefebvre's (1991), relatively more territorialised, notion of social space is three-dimensional, consisting of perceived ('spatial practice'), conceived ('representations of space'), and lived ('representational spaces') space. Focusing on discourse, this article is chiefly occupied with conceived space; that is, the space constructed by 'scientists, planners, urbanists, technocratic sub-dividers...social engineers (Lefebvre, 1991, p. 31), and other groups in society. However, in line with Lefebvre's trialectic as well as the aggregate anaIytical framework utilized by this study, this article recognises the production of space as a multidimensional process involving all three layers of space. This implies, in short, acknowledging the role played by mobile technology discourse in the overall reproduction of power relationships (Bourdieu, 1977).

In addition to providing answers to the empirical questions posed above, the article includes a discussion about the potential implications of existing discourse overlaps between ICT companies and mediatisation theorists, as well as a sketch for a research agenda for critical constructivist mediatisation studies.

\section{Theoretical Framework}

The present article positions itself against deterministic claims about technology as the driver of social change but accepts that media technology can be one potential source of transformation. In taking this position, the article aligns with three distinct yet interrelated theory fractions, which form the analytical framework of this study. Next to mediatisation theory, the article incorporates insights from the social construction of technology (SCOT) paradigm and technology discourse theory. These theory fractions are interrelated in that they all embrace social constructivism yet distinct in that they still tend to be differently biased in terms of where agency is primarily located: if mediatisation research thus far has been chiefly interested in the ways in which technology shapes the social, SCOT (e.g., Humphreys, 2005; Pinch \& Bijker, 1984) tends to accentuate the impact of the social on technology. Hence, combining mediatisation theory and SCOT means finding a fruitful middle-way between technological and social 'determinism' (Latour, 2005). What both frameworks have payed less attention to, however, is the role of discourse in the construction of the social, including technology. Since technology discourse perspectives (e.g. Fisher, 2010a, 2010b) tend to emphasise the reciprocity between discourse and reality precisely, they offer a valuable, third, point-of-entry into this article's object of study. In the end, the combination of mediatisation theory, SCOT, and technology discourse theory enables critical examinations of how technology discourse contributes to the production of social space. It equips us to scrutinise imagined user modes (who is supposed to use what technology in what way?), imagined user contexts (where is technology supposed to be used?), and ultimately questions of inclusion and exclu- sion (who is part/not part of the 'mobility revolution'?). In the following sections, the study's theoretical framework is elaborated.

\subsection{Mediatisation as Media Indispensability}

'Mediatisation' is a contested concept (Deacon \& Stanyer, 2014; Hepp, Hjarvard, \& Lundby, 2015) and parts of the debate has evolved around the 'question of technology' (Jensen, 2013, p. 215). Theorists employing a social constructivist outlook on mediatisation have been particularly prone to promote 'non-media-centric' (cf. Morley, 2009) or 'holistic' (Jansson, 2013) mediatisation studies that contest the technological determinism usually associated with medium theory (Hepp \& Krotz, 2014; Jensen, 2013). Hepp and Krotz (2014) are among those who argue for the usefulness of social constructivist approaches to mediatisation and define, accordingly, mediatisation as 'a concept used in order to carry out a critical analysis of the interrelation between the change of media and communication, on the one hand, and the change of culture and society on the other' (Hepp \& Krotz, 2014, p. 7). They conceptualise mediatisation partly by explaining the differences between mediatisation research and medium theory (McLuhan, 1964; Meyrowitz, 1986) and critique, among other things, the medium theorist idea that each society is dominated by a single medium. Such a perception, they claim, is invalid, especially in today's trans-medial landscape where various media are inescapably intertwined: 'It's not just the mobile phone that makes the difference for our present everyday lives, but how the mobile phone interacts with social media, e-mail, digital television, and so on' (Hepp \& Krotz, 2014, p. 9).

Mediatisation theory, contrary to medium theory, recognises media influence 'beyond simple casual effects' of particular media technologies (Hepp, 2012, p. 17). Hepp's (2012) conceptualisation of mediatisation as processes of 'moulding' is in turn embedded in Jansson's $(2014,2015 b, 2018)$ critical media indispensability approach to mediatisation, which understands mediatisation as 'a movement through which media technologies and related artefacts become necessary for carrying out practices that are essential to the maintenance of society in its various parts, and places and practices become materially adapted to the existence of media' (Jansson, 2014, p. 275). However, as Jansson (2014) points out, media technologies do not become indispensable unless they get meaningfully integrated in life at large. How, then, might such integration occur?

In order to reach a fuller understanding of how media become indispensable, to people and to societies at large, it is useful to consult the analytical toolbox provided by Schulz (2004). Schulz suggests four processes through which mediatisation is realised: extension, substitution, amalgamation, and accommodation. Influenced by medium theory, Schulz acknowledges that media extend the possibilities of communicating across 
time, space, and in different modes. Additionally, media can entirely or partially replace, or substitute, social activities (i.e., video gaming substituting face-to-face gaming). Another tendency is that non-media-related activities merge with, or amalgamate, media-related dittos. Lastly, Schulz argues that various spheres of social life become increasingly affected by a 'media logic' (2004, p. 89). Thus, other societal institutions tend to accommodate such a media logic in the sense that they, consciously or unconsciously, adjust their acting to the media.

Schulz's (2004) theoretical framework can be used to operationalise Jansson's media indispensability approach and has informed my analyses of contemporary mobile media discourse. Ultimately, Schulz's typology of mediatisation points to the complex relationship between technology and the social, albeit with an obvious focus on the former's effects on the latter. Thus, in order to prepare for an even more reflexive approach to the technology/social relationship, I will now introduce the interrelated but 'inverted' perspective offered by the SCOT paradigm. In addition to serving as a complement to mentioned mediatisation theory, SCOT is also valuable in that it accentuates power inequalities between different social groups.

\subsection{The Social Construction of Technology}

Reading technology as a social construct is at the core of the SCOT framework. Pinch and Bijker (1984) created SCOT for discerning how 'relevant social groups' negotiate the meaning of technological artefacts. 'Social group' refers to institutions and organisations as well as organised or unorganised groups of individuals, a key requirement being that 'all members of a certain social group share the same set of meanings, attached to a specific artefact' (Pinch \& Bijker, 1984, p. 414). A fundamental notion to SCOT is that different social groups have different problems to solve as well as different technological solutions to those problems. The inevitable consequence is that artefacts tend to be subjected to 'interpretative flexibility' (Pinch \& Bijker, 1984, p. 419). The right to define a technological invention-and to bring 'rhetorical closure' (Pinch \& Bijker, 1984, p. 426) to controversy-is fought over by different social groups, differently positioned in social space depending on their resources (or, forms and amounts of capital, to speak with Bourdieu, 1977, 1989).

For this article, Humphreys' (2005) reframing of the 'relevant social groups' concept into four main groupsproducers, advocates, users, and bystanders-is especially valuable. The producers include those who have a vested economic interest in the continued proliferation of a technological artefact' (Humphreys, 2005, p. 235). Humphreys adds to this group not only engineers and designers, but also advertisers and marketers. 'Through language', she acknowledges, 'marketers and advertisers play an important role in determining how people understand a technology' (see also MacKay \& Gillespie, 1992, for similar arguments). By this token, discursive practices play a momentous role in the SCOT, as in the making of reality at large (cf. Berger \& Luckmann, 1966; Foucault, 1972; Schutz, 1967).

Before continuing the technology (as) discourse perspective, a short note should be made around the usefulness of SCOT for studying the social construction of mobile media. SCOT was built for scrutinising the construction of particular technological artefacts, such as the bike. My study, however, concerns 'mobile media' as an assemblage of technologies (i.e. as cloud infrastructures, mobile broadband, mobile phones, portable tablets, etc.) rather than a specific medium (utterly, my understanding of 'mobile media' is informed by the technology discourse studied). This approach, in turn, corresponds with Hepp and Krotz's (2014) previously presented critique of medium theory. As they argue, the contemporary media landscape is essentially trans-medial, and today's analytical models must hence acknowledge the increasingly complex interrelations between media. Thus, whilst my appropriation of SCOT might go against Pinch and Bijker's (1984) original intent, I would argue that analyses of the social construction of 'mobile media' have much to gain from being - at times at least-non-media-specific.

\subsection{Technology (As) Discourse}

Technological inventions are surrounded by 'myth'; by more or less phantasmagorical statements about their 'goodness' (Robins \& Webster, 1999, p. 151). Technology producers face the delicate challenge of presenting new media artefacts as unfrightening, even mundane, and at the same time 'magical' (Mosco, 2004). Marvin's (1988) essayistic exploration of discourses surrounding electricity and telephony in the late $19^{\text {th }}$ century discloses how this challenge was dealt with by different social groups and manifested in various accounts of the new inventions. Marvin stresses how conflicting discourses on what the technology should do and for whom were produced by, on the one hand, the powerful 'experts' who struggled to maintain the right to define the technology in question and, on the other hand, the less informed 'public'. By expounding how these conflicts in turn reflected larger social battles of the late $19^{\text {th }}$ centurybetween dominant and dominated classes, genders, ethnic groups, etc.-Marvin's work demonstrates the power of discourse to structure the social world.

The structuring powers of discourse were also of concern to Foucault (1972), who regarded discourse as fundamental to legitimisation processes. Habermas (1971), furthermore, theorised the ideological functions of technology discourse specifically. Following Habermas, Fisher (2010a) proposes that contemporary technology discourse constitutes a legitimation discourse for post-Fordist capitalism: 'Post-Fordist social relations are not the inevitable social consequences of technological innovations...but also the result of discursive practices which have made such social transformations seem natural, neutral and inevitable, precisely because they 
are presented as ultimately technological (p. 244). This points to the complex relationship between technology, discursive practices, and society: technology discourse tends not only to make social transformations seem universal-to the extent that 'everybody', 'everywhere' is included (cf. Hand \& Sandywell, 2002; Poster, 2008), it also presents social space as essentially homogenous and free from conflict.

However, as we know from earlier research, the power to define what various technologies should be, or for whom, is unevenly distributed across social space (Marvin, 1998; Russell, 1986), as is technology access per se (Ragnedda \& Muschert, 2013). In addition, there are moral dimensions to media use that may spur or hamper individuals' engagement with particular technologies, in particular contexts. In Bengtsson's (2011) words, various 'imagined user modes' guide our daily interactions with the media. These modes, she explains, 'are not related to the media text or technology in itself, but rather to ideas of different technologies and texts and, more specifically, to ideas of how they affect their users' (Bengtsson, 2011, p. 193, original emphasis). Although Bengtsson stresses that there is not one source to these modes but rather that they form as a combination of personal value systems, culturally constructed norms, and the specific traits of a medium and its content, corporate technology discourse is a source rich in ideas about what constitutes proper media use for different social groups.

\section{Data and Method}

Technology discourse emerges in various social contexts. This article limits itself to accounts and statements by multinational ICT companies IBM, Huawei and Ericsson. IBM is headquartered in New York, U.S. and describes itself as 'a cognitive solutions and cloud platform company' (IBM.com, 2018). IBM was incorporated in 1911 as a hardware company, but has over the years moved its operations to software and services. Currently, IBM operates in around 170 countries and through five segments: Cognitive Solutions, Global Business Services (GBS), Technology Services \& Cloud Platforms, Systems and Global Financing (IBM.com, 2018). Revenue was $\$ 80$ billion in 2016. Huawei Technologies Co., Ltd. presents itself as ‘a leading global information and communications technology (ICT) solutions provider' (Huawei.com, 2018). The company is headquartered in Shenzhen, China, and has since its founding in 1987 expanded its business from phone switches to telecommunications networks, operational and consulting services, and equipment aimed at enterprises. Huawei also produces communication devices for the consumer market. Huawei operates in around 170 countries and revenue was $\$ 75.1$ billion in 2016. Telefonaktiebolaget LM Ericsson was founded in 1876 and soon became one of Scandinavia's top telephone suppliers. The company is headquartered in Stockholm and operates in around 180 countries. Ericsson presents itself as 'a world leader in the rapidly changing environment of communications technology-providing equipment, software and services to enable transformation through mobility' (Ericsson.com, 2018). Revenue in 2016 was $\$ 26$ billion.

The companies were selected as cases first and foremost because of their strong positions and hence impact in the mobile communications market, but also because their aggregate operations cover the full spectrum of existent mobile technologies: from mobile devices and software to supporting technological infrastructures, such as mobile broadband, cloud technologies, 'smart' systems, etc. All companies are advocates of the 'mobility revolution' and sell mobile media technologies. Studying ICT corporations, this article concentrates on one of the most influential social groups identified by Humphreys' $(2005$, p. 234$)$ - the producers, who have an organisational/economic stake in technology.

Discourse has been described as 'a certain 'way of speaking' (Foucault, 1972, p. 193). This particular study is limited to corporate technology discourse. Corporate discourse refers to 'the set of messages that a corporation chooses to send to the world at large and to its target markets or existing customers' (Breeze, 2013, p. 19). The larger linguistic units studied include material typically sorted under the 'Investor Relations' rubric on the organisations'. Annual reports are at the core of this study, but has-following David (2001)-been contextualised through collection of related material from the corporate websites, i.e., white papers (e.g. IBM's Return on Mobile), in-house articles (e.g. from Ericsson's Technological Review), blog posts (e.g. Ericsson's The Networked Society Blog [which over the course of the study became The Big Ideas Blog: Transformation through Mobility]), other reports (e.g. IBM's Individual Enterprise: How Mobility Redefines Business) and advertisements. In the annual reports, the narrative sections have been of primary interest. These include the executive's letter and summaries of operations, typically accompanied by eye-catching illustrations. Tinker and Neimark (1987) stress that such texts 'play an important part in forming the world-view or social ideology' (p. 72). Compatible perspectives are also offered by David (2001), who writes specifically on mythmaking in annual reports. These types of 'workplace documents', he explains, are typically 'not isolated in one business but reflect and influence the wider political, institutional, social, and legal policies of the culture' (David, 2001, p. 196). What is more, the myths that these documents build tend to influence other domains of communication, such as newspaper discourse or marketing (David, 2001).

In terms of data selection, all annual reports retrievable on the corporate websites (81 in total) were downloaded (IBM all years 1994-2016; Huawei all years 20062016; Ericsson all years 1970-2016). Given the purpose of this study, particular attention has been paid to statements about mobile technology (which, due to the key role played by such technology in the selected corporations' operations is highly present in the studied mate- 
rial). The same principle was applied in the selection of the contextualising corporate communication from the websites. All materials have been stored electronically and in print, and have been subjected to a qualitative analysis that considers written discourse as well as visual representations. In the selection of examples, representativeness has been a guiding principle. Hence, I have primarily illustrated my findings with quotes and imagery that are typical rather than atypical for the analysed linguistic units.

\section{Findings}

This empirical section demonstrates how the media indispensability trope is constructed by IBM, Huawei, and Ericsson, and in continuation how contemporary corporate technology discourse constructs the media-social space juncture. I begin by exemplifying how the 'mobility revolution', at large, is constructed, and continue with a systematic analysis guided by Schulz's (2004) typology of mediatisation to deconstruct the notion of media indispensability (Jansson, 2014, 2015b, 2018).

\subsection{Mediatisation as a Human Drive and Natural Force}

The strongest message communicated by IBM, Huawei and Ericsson is that the world is undergoing significant and rapid change due to technological advancement. This narrative cuts across all of the most recent annual reports, from all three corporations. In their 2011 annual report, for example, IBM states that 'Without question, the world is undergoing disruption' (IBM, 2011, p. 4). Ericsson echoes the rhetoric in their 2015 annual report, claiming that 'We are living in a truly remarkable time. The pace of change in society, in our industry and within Ericsson has never been faster' (Ericsson, 2015, p. 2). Huawei, correspondingly, writes in their 2014 annual report of 'the coming industrial revolution' (Huawei, 2014, p. 2) and predicts that 'The future fully-connected world will have a far-reaching impact on every individual, organisation, and industry' (2014, p. 2). Technological advancements in the domain of mobile media are attributed particular transformative powers, as illustrated by this statement by Ericsson:

The potential of the Networked Society lies in transformation through mobility. Transformation in the way people organize their individual lives and carry out vital tasks. Transformation in the way we work, the way we share information, and the way we do business. Transformation in the way we consume and the way we create. (Ericsson, 2016, p. 1)

Ericsson's 'Networked Society' has its parallel in Huawei's vision of a 'Better Connected World'. This connected world, as stated by Huawei in their 2014 annual report, responds to an 'enduring human drive' for connectivity across spatial and temporal boundaries. In this world, fur- thermore, mobile and connected media will drive 'global progress' and 'improve work and life for all' (Huawei, 2014 , p. 2). IBM, on their part, claims that what we anticipate is an 'emerging global culture, defined not by age or geography, but by people determined to change the practices of business and society' (IBM, 2013, p. 2). Ericsson is equally prone to praise the equalising powers of mobile technologies: 'Mobile broadband decreases geographical and socioeconomic gaps and improve life quality across the globe' (Ericsson, 2012, p. 14). In their recent Networked Society Essentials brochure, Ericsson further explains what the networked society means for our 'future' and 'planet':

The Networked Society is not really about the connections however, but rather about the impact these are having on our world. It's about new ways for us to collaborate, share and get informed. It's about innovative ways of doing business that are creating efficiencies in the public and private sectors. And it's about how we can shape the future together and find solutions to some of the greatest challenges facing our planet. (Ericsson, 2016, p. 2)

Thus, in line with much globalisation theory-or what Bude and Dürrschmidt (2010) have criticised as 'flowspeak'-IBM, Huawei and Ericsson present mobile media as means to create a world without borders. Mobile devices are hence promoted as 'technologies of the cosmos' (Tomlinson, 2008) that invite participation in a global, deterritorialised, culture (Giddens, 1990). The frequency of utterances like 'everyone', 'for all', 'global culture', 'everywhere', 'the world', 'across the globe' and 'every individual' across the linguistic units of analysis is striking and contribute to the establishment of a cosmopolitan ethos in studied texts. The McLuhanian metaphor of the world as a 'global village', where everyone is connected through media, is repeatedly communicated, albeit in varied wordings. The seeming inevitability of this development frames mediatisation as a democratic natural force that sweeps the globe. As illustrated by Figures 1 and 2, this world is typically represented through ultra-urban imageries connoting highspeed, metropolitan, lifestyles (this is a point that we shall return to).

According to Ericsson, the networked society is a society 'where every person and every industry is empowered to reach their full potential' (Ericsson, 2016, p. 1). Along the same lines, Ericsson's narrative recognizes that we are currently living in 'the age of empowerment' (quote from Ericsson's slideshow 'The Networked Society', retrieved from Slideshare.net, September 12, 2017). Thus, mobile media are not only constructed as means of social change on a global, collective, level, but also as means of individual empowerment (see Figure 3). Mobile media are ultimately constituted as 'technologies of self' (cf. O'Flynn \& Petersen, 2007, p. 468) by which individuals can take control over their life-situation. Thus, in par- 


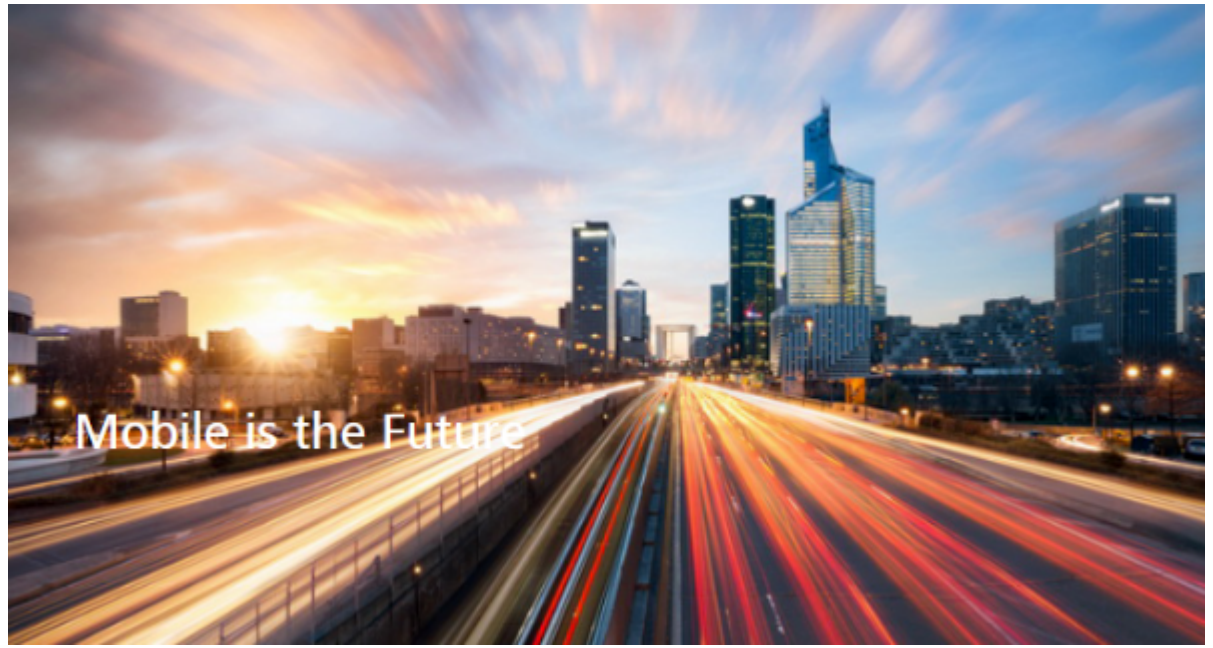

Figure 1. Visionary imagery retrieved from Huawei's official website, July 10, 2017.

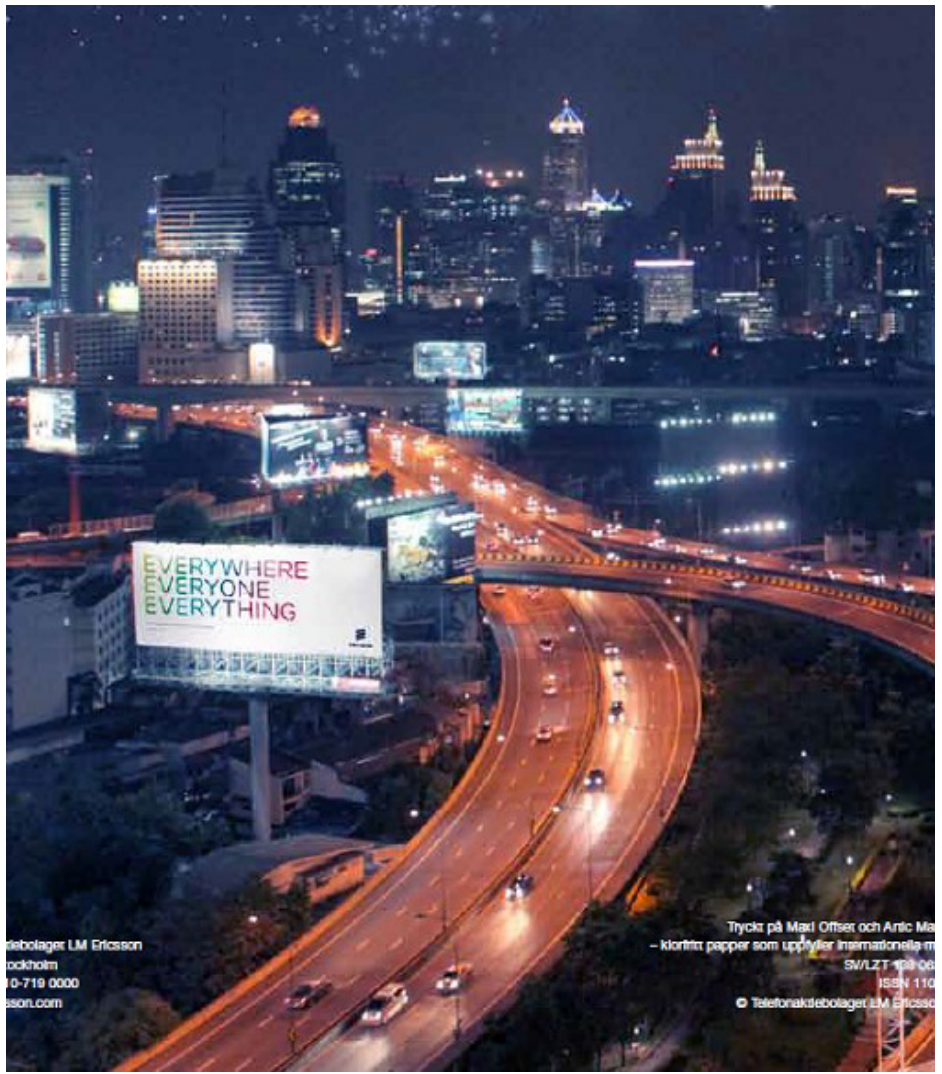

Figure 2. 'Everywhere, everyone, everything'. Cover of Ericsson's Annual report 2012.

allel with the visionary cosmopolitan narrative is an individualistic, neoliberal, 'enterprise-self' jargon (cf. Foucault, 1977, on self-disciplining) that runs across all three cases of corporate communication. As we shall see later, this kind of discourse is particularly manifest in narratives about technology-driven transformations of work.

\subsection{Media and Social Change-A Schulzian Approach}

Representations of mobile media as extensions of man (Schulz, 2004) contribute to the construction of media indispensability. Mobile media, the corporate texts pro- pose, enable connectivity 'whenever' and 'wherever'. Technology is hence claimed to abolish temporal and spatial borders and enable long-distance and immediate connectivity. Visually, this theme is typically presented through images of technology use in shifting social contexts, such as the home, office, beach, subway, etc. (Figure 4).

Present in the studied material is, thus, also a narrative on media ubiquity, which in turn stimulates the idea of 'placelessness' (Meyrowitz, 1986): 'With mobile broadband, you're not tied down by a cable, or even by a wireless hotspot. Wherever you're going, what- 


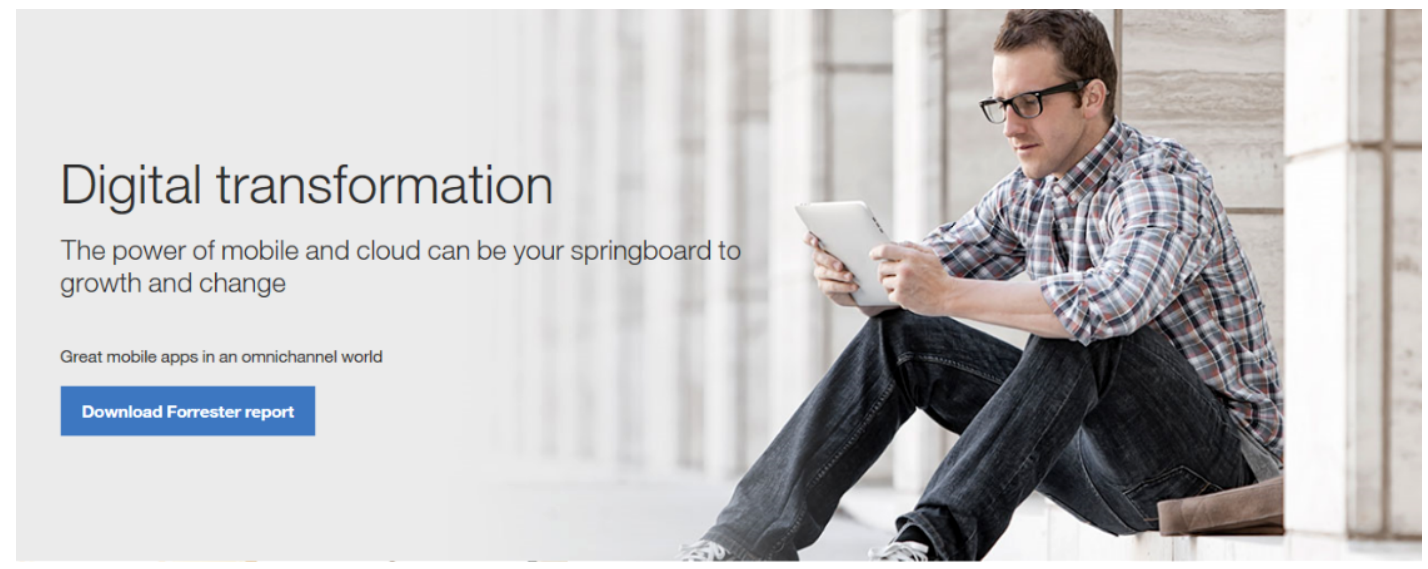

Figure 3. Screenshot from IBM's website, February 22, 2017.

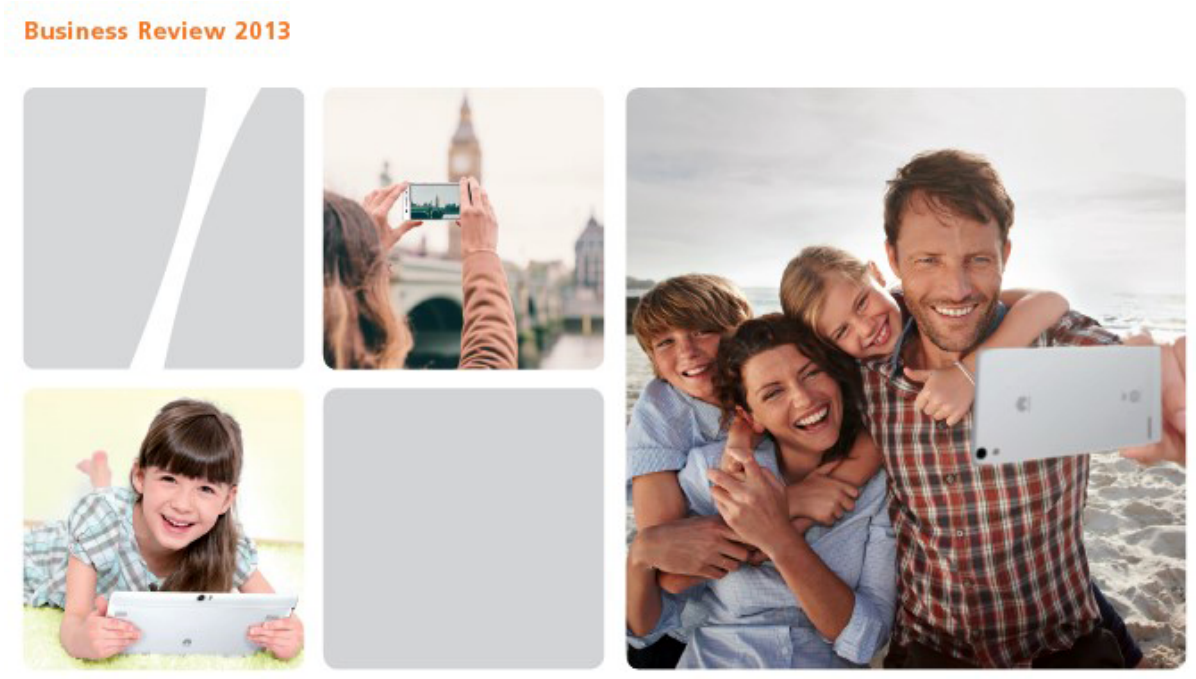

Figure 4. Ubiquitous media. Imagery from Huawei's Annual report 2013 (p. 23).

ever you're doing, you take the world with you' (Ericsson, 2010, p. 2). As stated by Ericsson, the spatialtransgressive connectivity provided by mobile media, enable new ways of organising life. What media mobility means for work life is particularly articulated in researched corporate documents, and all three corporations have webpage sections and reports dedicated to this theme.

It is also in the work context that the media as substitution (Schulz, 2004) theme is most apparent. Mobile media are promoted as replacements of face-to-face interactions and 'good work', the corporate jargon suggests, involves mobile solutions. As found also by Fisher (2010a), there are remarkable similarities between corporate technology discourse and post-Fordist capitalist discourse. Overall, work with mobile media is described as 'smart', 'effective', 'flexible', 'engaging', and 'empowering'. Under the headline 'Reimagining Work' in their 2014 annual report, IBM offers a vision of future work life, in which 'systems of engagement' will drive businesses and redistribute power from employers to employees (IBM, 2014 , p. 14). The blurring of boundaries between work life and private life that mobile media contribute to- a trend oftentimes criticised for its potentially negative effect on mental health, family life, workers' rights, etc. (e.g., Gregg, 2011)-is typically embraced, as illustrated by this statement in Ericsson's 2013 annual report:

social media and communication services are eroding the borders between private and professional lives....The blurred boundaries between work and private life also change our understanding of what it means to work. When restrictions in terms of time and geographic location become obsolete, more people can work more effectively in a global workplace. (p. 133; author's translation)

Huawei also constructs mobile media, and mobile internet, specifically, as a 'game changer for billions of people, both at work and in their personal lives' (Huawei, 2015, p. 15). Mobile technologies are presented as 'digital assistants' that 'can help coordinate your life and work schedules anytime and anywhere' (Huawei, 2015, p. 18).

Judging from the visual representations accompanying these visionary statements, mainly white-collar jobs are affected by these changes. This, in turn, corresponds 
to a general observation regarding the visual representation of technology in the studied material. The mobile media technologies are predominantly inserted into urban milieus and placed in the hands of seemingly capital rich 'knowledge-workers' (Figures 5 and 6; revisit also figures 1-4). When images of subordinate classes or other types of workers do appear, it is chiefly in relation to the cosmopolitan narratives or under document headings like 'corporate social responsibility', 'sustainable development' or 'global perspectives'. In those cases, photos typically display media use in remote villages in developing countries, so as to prove the transformative potential of the technology. In short, forms of mediatised 'privileged mobility' (Polson, 2016; Tesfahuney \& Schough, 2016)-including commuting to/from workare typically presented in Western (or at least Westernized), metropolitan, cities, whereas media-induced 'social mobility' tend to be exemplified through imagery from rural milieus in non-Western(-ised) areas Figure 7).

To the extent that seemingly capital rich subjects are portrayed in non-urban settings, this is mainly while performing other types of privileged mobility, most notably connected to tourism, sport, and leisure. Outside of office environments, mobile media devices are typically displayed in remote, previously non- or at least less mediated, places. Representations of such activities also correspond with Schulz's (2004) notion of amalgamation, or the integration between mediated (e.g. GPS-tracking or photography) and non-mediated activities (e.g., mountain climbing or hiking). Also corresponding to this notion are the frequently used concepts of 'smartness' and 'Internet of Things'. 'Smart' homes, cars, cities, workplaces, even bodies, (cf. Rose, 2018) represent the true collapse of mediated and non-mediated spaces and practices. Thus, the indispensability of mobile media is further rein- forced in narratives pertaining to what Couldry and Hepp (2016) refer to as deep mediatisation; 'where every element of social process and social life is composed of elements that have already been mediated'. No areas of life, the corporate texts suggest, are untouched by the ongoing technological transformations. Connected things are portrayed as key to the 'Networked Society' envisioned by Ericsson as well as to the 'Better Connected World' imagined by Huawei. Ultimately, Huawei foresees a total integration of 'the physical world' and the 'digital world' (Huawei, 2015, p. 15). 'Humanity', the company foresees, 'will soon enter a fully connected age, where the heartbeat of humanity will soon be as much digital as it is physical' (Huawei, 2015, p. 16). Using the language of biologism, thus, Huawei presents ongoing transformations as immanent to human nature.

It lies in the interest of communication corporations to accentuate their significance not only as enablers of 'social change' and 'individual empowerment', but also as pivotal to the economy at large. Hence, what Schulz's (2004) refers to as accommodation is primarily acknowledged and promoted as a 'mobile media logic' (Henrique \& Damasia, 2016) that affect other societal institutions, most notably other businesses. Such a mobile media logic is identified by all three corporations (albeit not conceptualized as such) and corresponds to the 'empowering' 'flexibility' discourse described earlier. The opening page of IBM's annual report from 2016, with its personal tone of address, is illustrative: 'Every profession in every industry in every part of the world is changing, simultaneously. You are drawing on a wealth of new data, knowledge, insights, and tools. You are being equipped to rethink your job, and freed to do your life's work' (IBM, 2016, p. 1). Ericsson shares IBM's vision and stresses that 'Digitalization and information flows are

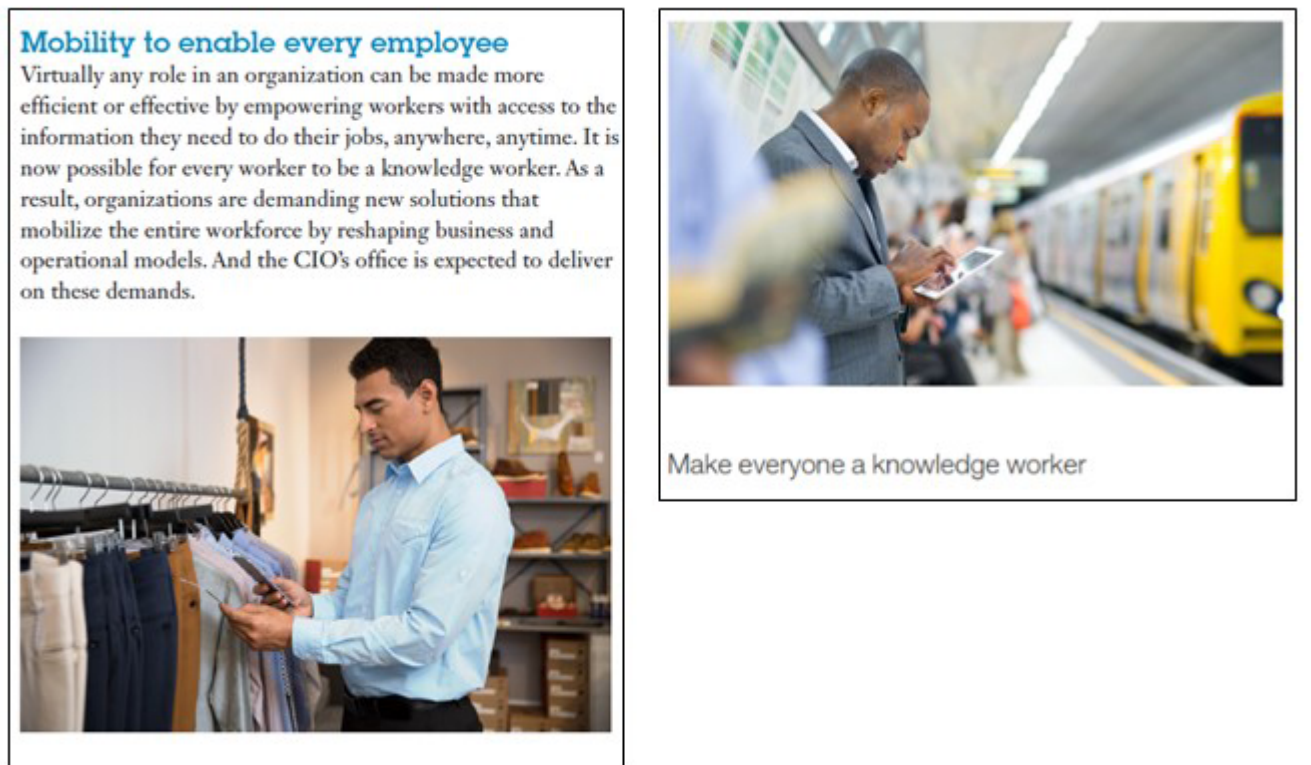

Figure 5. (left): Image retrieved from IBM's MobileFirst Whitepaper, 2016 (p. 2).

Figure 6. (right): Image retrieved from IBM's official website IBM.com, July 10, 2017. 


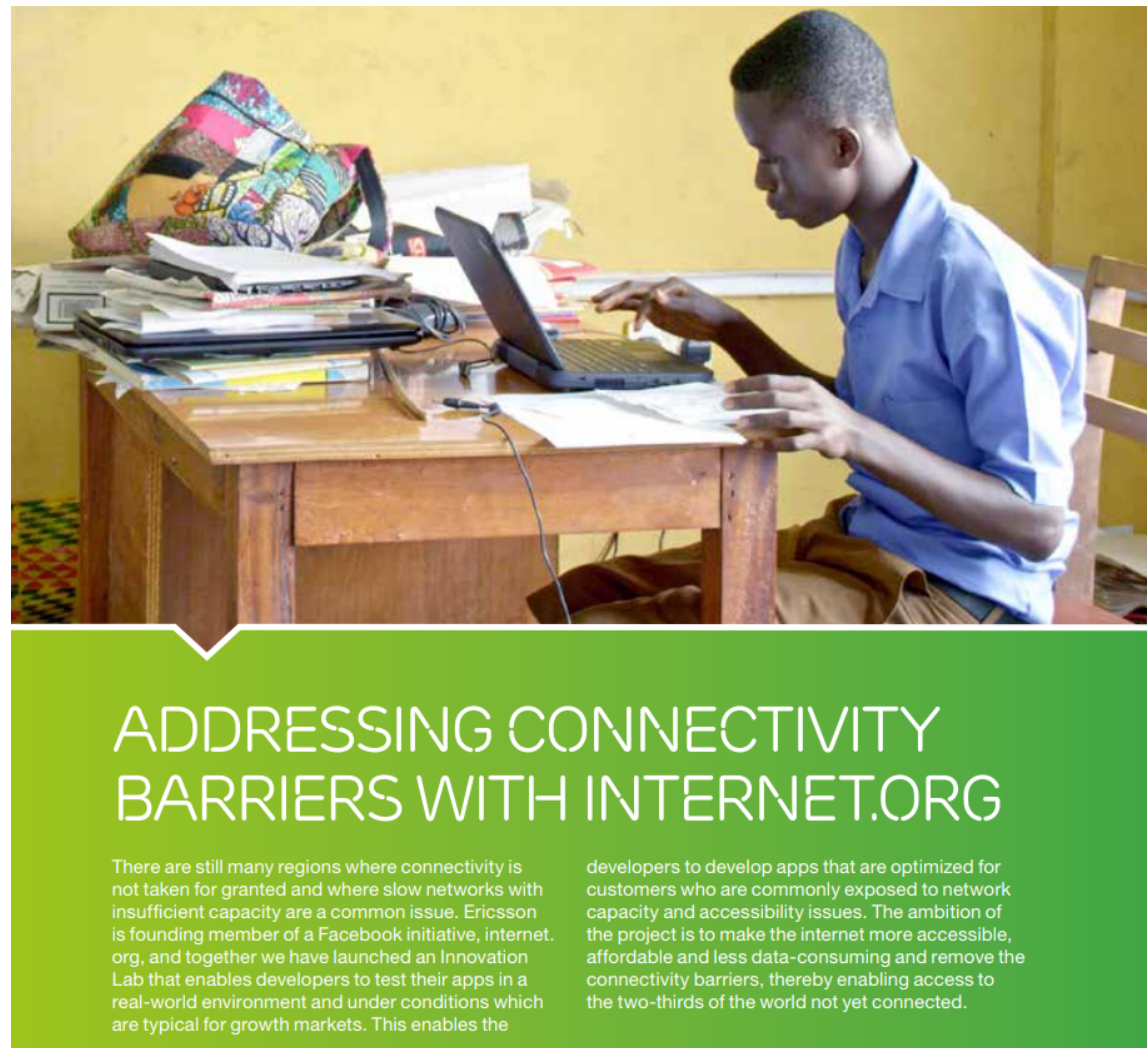

Figure 7. Technological emancipation. Source: Ericsson's 2014 annual report (p. 40).

enabling organizations to work in new ways' (Ericsson, 2013, p. 133). Ericsson's statement, in turn, is remarkably similar to Huawei's depiction of what new media technology will mean for businesses outside of the ICT industry: 'The Internet of Things, e-Commerce, and digital media among others are driving the upgrading and restructuring of traditional industries' (Huawei, 2012, p. 5). What is more, Huawei is explicit about the consequences for those businesses who do not keep up with the latest innovations: 'With full connectivity, enterprises in every industry will digitise their business systems, and those who fail to go digital will perish'. (Huawei, 2015, p. 16, emphasis added). While unusually drastic, Huawei's fatal statement in their 2015 annual report is symptomatic of the technology discourse produced by all three corporations studied. It is the inverted version of all the celebratory claims about what mobile media technologies will do for society, businesses, and individuals that have been illustrated in this section. Hence, what IBM, Ericsson, and Huawei ultimately sell are non-optional technologies of life.

\section{Summary of Findings}

This study was guided by social constructivist outlooks (e.g. Berger \& Luckmann, 1966; Marvin, 1988; Pinch \& Bijker, 1984; Williams, 1974), meaning that society and language have been recognised as mutually constitutive. By this token, I have argued that the ways in which ICT corporations represent technology have implications for how we think of, relate to, and practice technology. Researched corporations contribute to the construction of the 'mobility revolution', both discursively and materially. They all propose that media mobility brings a radical break with the past and that life without media is not only unimaginable, but also poor, complicated, and dull. Mediatisation is constructed as the response to an internal human drive and as an inexorable natural force. Three sub-discourses were identified in the empirical data of this study: 'technologies of cosmos' (cf. Tomlinson, 2008), 'technologies of self' (cf. O'Flynn \& Petersen, 2007), and, ultimately, 'technologies of life'. While biased somewhat differently, these sub-discourses all communicate the indispensability of mobile media in modern lives. The 'technologies of cosmos' discourse echoes 'flow-speak' (Bude \& Dürrschmidt, 2010) and renders mobile media necessary for social and cultural change on a collective level, whereas the 'technologies of self' discourse presents mobile media as essential for personal growth and self-empowerment (cf. Gill, 2014). The 'technologies of life' discourse is arguably the most extreme one, in that it constructs mobile media as engrained in human life per se and hence completely vital. This latter discourse constructs something close to the posthumanic figure 'the cyborg citizen' (Gray, 2000, p. 20). Altogether, IBM, Huawei, and Ericsson present themselves as the purveyors of a global mobile technotopia where 'everybody' can feel at home. The mobile media they provide are constructed as 'a component of universality' (Poster, 2008) promoting 'global citizenship' (Hand \& 
Sandywell, 2002, p. 198). This is a kind of globalism discourse that has been successfully upheld for a long time (Poster, 2008, traces it back to the Enlightenment and specifically to Kant's Idea for a Universal History from a Cosmopolitan Point of View from 1784).

\section{Concluding Discussion}

In this concluding section, I shall reflect upon some potential implications on the aggregate technology discourse on social space (Bourdieu, 1977; Lefebvre, 1991) and suggest an agenda for critical media(-tisation) studies that aims to stimulate interpretive flexibility (Pinch \& Bijker, 1984).

Let us begin by considering the legitimising and reproductive powers of studied corporate technology discourse. This is imperative if we accept that technology discourse both 'reflect and influence the wider political, institutional, social, and legal policies of the culture' (David, 2001, p. 196), and operates ideologically (Fisher, 2010a; Habermas, 1971). In times when Forbes magazine writes instructions for how to do 'digital detox' (Goldston, 2018), when entrepreneurs offer ' $5: 2$ digital diets', and when concepts like 'counter-mediatisation' (Jansson, 2018, p. 156, emphasis added) gain momentum, there are indeed reasons to question the legitimacy of celebratory discourse on the 'mobility revolution'. Relatedly, when corporations provide employees with 'workfulness' handbooks (Telenor, 2017), when French students protest against 'flexploitation', and when academics write about the 'tyranny of the mobile phone' (Gregg, 2011, p. 3), we should troubleshoot commemorative accounts of technologies that let us work 'whenever', 'wherever'. If we add to this picture perspectives that recognise media usage per se as a form of (free) labour (Fuchs, 2014; Terranova, 2000), then petitions for more digital engagement should be further problematised. As found also by Fisher (2010a), the affinity between new media discourse and the current mode of capitalism is evident. In promoting accelerated, urbanised, always-onthe-move, self-organised lifestyles, corporate technology discourse potentially reinforces (self-)precariousness in both material and perceptive terms and thus serves the interests of capitalism. This in turn corresponds with critical understandings of mediatisation as a hegemonic force. As Jansson (2018) argues: 'The need to stay connected, make oneself visible and adapt one's free time and working life to the affordances of media cannot be uncoupled from the political-economic forces of a capitalist consumer society' (p. 155). The hegemonic nature of mediatisation also proves itself in the construction of mobile media users. While global inequality is addressed in the studied texts (as something to be solved by technology; cf. Figure 7), whereas people in economically less prosperous parts of the world do feature in the material (typically as to illustrate the remarkable reach of the 'revolution' or as targets for 'social good' campaigns), and although IBM, Ericsson, and Huawei do seem to strive for ethnic as well as gender diversity in their overall imagery (while no quantitative analysis has been made on my part, I would appreciate the ratio women/men to be more equal than suggested by the illustrations selected for this paper), there is considerably less diversity in terms of class. The pervasiveness of white-collar professionals in modern cityscapes is apparent. Potentially, this class bias is connected to the high levels of 'selfentrepreneurial' narratives in the corporate texts. As Gill (2014) finds in her examination of the classed dimensions of entrepreneurial discourse, 'class hierarchy is simultaneously present and erased by entrepreneurialism and other, intersecting discourses' (p. 65). Legitimate entrepreneurship, Gill (2014) concludes, is reserved for 'the creative, experienced, white, professional middle and upper classes' (p. 60). In conclusion then, the glory of mediatisation is sold by way of intended users whose position in social space is already privileged. Again then, we are reminded that the 'universality' promoted by global discourse is not always so widespread after all (cf. Poster, 2008).

Let us continue by reflecting upon the implications of mentioned findings on media(-tisation) research. While the presented study is delimited to an interrogation of the discursive construction of mediatisation-how media indispensability is constructed as trope-the question of whether or not media indispensability is merely a trope merits attention. Numerous empirical studies imply that media indispensability is more than simply a key selling-point for ICT corporations and more than an alluring theoretical figure in mediatisation studies. The media indispensability trope is indeed-also-a reflection of society beyond investor reports and marketing texts. McLuhan's view on media as human extensions, Schulz's (2004) recognition of substitution, amalgamation, accommodation as additional tokens of progressed mediatisation, and Hepp and Couldry's (2016) account of 'deep mediatisation' all suggest that the media do reconfigure social life-as does Jansson's (2014, 2015a, 2015b, 2018) take on mediatisation as 'media indispensability'. Arguably then, there are solid grounds for both ICT corporations and academics to cast media technologies as drivers of social change (next to other meta-processes). Against this backdrop, it is understandable that ICT businesses and mediatisation researchers share ontologies-and metaphors. Figures like 'the networked society' (Castells, 1996) or 'global village' (McLuhan, 1964) have-apparently-been readily absorbed by ICT corporations. Conversely, 'cybertarianism' (Miller, 2016) is not exclusive to ICT investor reports, but appears in research literature as well (see Kaplan, 1990). Corporate rhetoric is innovative and the metaphors used are oftentimes alluring. It is therefore not surprising to find it influencing other social domains (David, 2001), research included. However, whilst corporate and research discourse might overlap, our agendas should remain different lest we give up the critical mediatisation studies project. This means, in essence, 
that when ICT corporations attempt to bring rhetorical closure to the debate by presenting a unified story on mobile media technology, mediatisation research should persistently supply alternative narratives so as to maintain interpretive flexibility (Pinch \& Bijker, 1984). Such narratives should also involve those agents whose position in social space-the capital poor, the 'peripheral'does not grant them a place in glossy corporate reports, yet who still-in the perspective of SCOT_-partake in the (social construction of) the 'mobility revolution'. Apropos the potential problems with discursive overlaps between corporate and mediatisation discourse: critical mediatisation studies must be careful not to be seduced by the 'classless ethos' (Gill, 2014) signifying contemporary mobile technology discourse. Granted that voices from various 'relevant social groups' are brought in, a discursive turn in mediatisation studies is welcome.

\section{Acknowledgments}

This study was part of the research program In-Between Spaces: Digital Media Geographies and Social Transformations in Small Towns, initiated by the Geomedia Research Group and funded by Karlstad University. The author is grateful to Mekonnen Tesfahuney, to the guest editors, and to the anonymous reviewers, for valuable comments on the manuscript.

\section{Conflict of Interests}

The author declares no conflict of interests.

\section{References}

Bengtsson, S. (2011). Imagined user modes: Media morality in everyday life. International Journal of Cultural Studies, 15(2), 181-196.

Berger, P. L., \& Luckmann, T. (1966). The social construction of reality. New York, NY: Anchor Books.

Bourdieu, P. (1977). Outline of a theory of practice (Vol. 16). Cambridge: Cambridge University Press.

Bourdieu, P. (1989). Social space and symbolic power. Sociological Theory, 7(1), 14-25.

Bourdieu, P. (1998). Practical reason. On the theory of action. Stanford, CA: Stanford University.

Breeze, R. (2013). Corporate discourse. London: A\&C Black.

Bude, H., \& Dürrschmidt, J. (2010). What's wrong with globalization? Contra 'flow speak' - Towards an existential turn in the theory of globalization. European Journal of Social Theory, 13(4), 481-500.

Castells, M. (1996). The information age: Economy, society and culture. Vol. 1. The rise of the network society. Malden, MA: Blackwell.

Centner, R. (2008). Places of privileged consumption practices: Spatial capital, the dot-com habitus, and San Francisco's Internet boom. City \& Community, 7(3), 193-223.
Couldry, N., \& Hepp, A. (2013). Conceptualising mediatization: Contexts, traditions, arguments. Communication Theory, 23(3), 191-202. doi:10.1111/ comt.12019

Couldry, N., \& Hepp, A. (2016). The mediated construction of reality. Cambridge: Polity Press.

Damkjær, M. S. (2017). Mediatized parenthood: The role of digital media in the transition to parenthood (Doctoral dissertation). Aarhus University, Aarhus, Denmark.

David, C. (2001). Mythmaking in annual reports. Journal of Business and Technical Communication, 15(2), 195-222.

Deacon, D., \& Stanyer, J. (2014). Mediatization: Key concept or conceptual bandwagon? Media, Culture \& Society, 36(7), 1032-1044.

Ekström, M., Fornäs, J., Jansson, A., \& Jerslev, A. (2016). Three tasks for mediatization research: Contributions to an open agenda. Media, Culture \& Society, 38(7), 1090-1108.

Ericsson. (2010). Annual report 2010. Retrieved from https://www.ericsson.com/en/investors/financial-re ports/annual-reports

Ericsson. (2012). Annual report 2012. Retrieved from https://www.ericsson.com/en/investors/financial-re ports/annual-reports

Ericsson. (2013). Annual report 2013. Retrieved from https://www.ericsson.com/en/investors/financial-re ports/annual-reports

Ericsson. (2014). Annual report 2014. Retrieved from https://www.ericsson.com/en/investors/financial-re ports/annual-reports

Ericsson. (2015). Annual report 2015. Retrieved from https://www.ericsson.com/en/investors/financial-re ports/annual-reports

Ericsson. (2017). Networked society essentials. Retrieved from https://www.ericsson.com/assets/local/public ations/white-papers/networked-society-essentialsbooklet.pdf

Ericsson.com. (2018). Ericsson's official website. Ericsson.com. Retrieved from https://www.ericsson.com/ en

Esser, F., \& Strömbäck, J. (Eds.). (2014). Mediatization of politics: Understanding the transformation of Western democracies. Basingstoke: Palgrave Macmillan.

Ewen, S. (2001). Captains of consciousness: Advertising and the social roots of the consumer culture (2nd ed.). New York, NY: BasicBooks.

Fast, K., \& Lindell, J. (2016). The elastic mobility of business elites: Negotiating the 'home' and 'away' continuum. European Journal of Cultural Studies, 19(5), 435-449.

Fisher, E. (2010a). Contemporary technology discourse and the legitimation of capitalism. European Journal of Social Theory, 13(2), 229-252.

Fisher, E. (2010b). Media and new capitalism in the digital age: The spirit of networks. New York, NY: Palgrave Macmillan. 
Foucault, M. (1972). The archaeology of knowledge (S. Smith, Trans.). London: Tavistock.

Foucault, M. (1977). Discipline and punish: The birth of the prison. New York, NY: Vintage Books.

Fuchs, C. (2014). Digital labour and Karl Marx. London: Routledge.

Giddens, A. (1990). The consequences of modernity. Cambridge: Polity Press.

Gill, R. (2014). 'If you're struggling to survive day-today': Class as optimism and contradiction in entrepreneurial discourse. Organization, 21, 50-67.

Goldston, N. J., (2018). Try it: Your 2018 'digital detox' guide. Forbes. Retrieved from https://www.forbes. com/sites/njgoldston/2018/01/24/try-it-your-2018digital-detox-guide/\#3a8579c05b4f

Gray, C. H. (2000). Cyborg citizen: Politics in the posthuman age. London: Routledge.

Gregg, M. (2011). Work's intimacy. Cambridge: Polity Press.

Habermas, J. (1971). Toward a rational society: Student protest, science, and politics. Boston, MA: Beacon Press.

Hand, M., \& Sandywell, B. (2002). E-topia as cosmopolis or citadel: On the democratizing and dedemocratizing logics of the Internet, or, toward a critique of the new technological fetishism. Theory, Culture \& Society, 19(1/2), 197-225.

Henriques, S., \& Damasio, M. J. (2016). The value of mobile communication for social belonging: Mobile apps and the impact on social interaction. International Journal of Handheld Computing Research (IJHCR), 7(2), 44-58.

Hepp, A. (2012). Mediatization and the 'moulding forces' of the media. Communications, 37(1), 1-28.

Hepp, A., Hjarvard, S., \& Lundby, K. (2015). Mediatization: Theorizing the interplay between media, culture and society. Media, Culture \& Society, 37(2), 314-324.

Hepp, A., \& Krotz, F. (2014). Mediatized worlds: Understanding everyday mediatization. In A. Hepp \& F. Krotz (Eds.), Mediatized worlds: Culture and society in a media age (pp. 1-15). London: Palgrave.

Hjarvard, S. (2008). The mediatization of religion: A theory of the media as agents of religious change. Northern Lights: Film \& Media Studies Yearbook, 6(1), 9-26.

Hjarvard, S. (in press). The Janus face of digital connectivity: The transformation of social dependencies. In J. Ferreira (Ed.), Between what is said and what you think: Where is mediatization? Santa Maria: FACOSFederal University of Santa Maria.

Hjarvard, S. (2013). The mediatization of culture and society. London: Routledge.

Huawei. (2012). Annual report 2012. Retrieved from http://www.huawei.com/en/press-events/annual-re port

Huawei. (2014). Annual report 2014. Retrieved from http://www.huawei.com/en/press-events/annual-re port
Huawei. (2015). Annual report 2015. Retrieved from http://www.huawei.com/en/press-events/annual-re port

Huawei.com. (2018). Huawei's official website. Huawei.com. Retrieved from http://www.huawei. com/en

Humphreys, L. (2005). Reframing social groups, closure, and stabilization in the social construction of technology. Social Epistemology, 19(2/3), 231-253.

IBM. (2011). Annual report 2011. Retrieved from https://www.ibm.com/investor/financials/financialreporting.html\#annual

IBM. (2012). Annual report 2012. Retrieved from https://www.ibm.com/investor/financials/financialreporting.html\#annual

IBM. (2013). Annual report 2013. Retrieved from https://www.ibm.com/investor/financials/financialreporting.html\#annual

IBM. (2014). Annual report 2014. Retrieved from https://www.ibm.com/investor/financials/financialreporting.html\#annual

IBM. (2016). MobileFirst whitepaper. Retrieved from https://www.ibm.com/mobilefirst/se/sv/downloads

IBM. (2017). The individual enterprise: How mobility redefines business. Retrieved from https://www935.ibm.com/services/multimedia/The_Individual_ Enterprise.pdf

IBM.com. (2018). IBM's official website. IBM.com. Retrieved from https://www.ibm.com/us-en

Jansson, A. (2013). Mediatization and social space: Reconstructing mediatization for the transmedia age. Communication Theory, 23(3), 279-296.

Jansson, A. (2014). Indispensable things: On mediatization, materiality, and space. In. K. Lundby (Ed.), Mediatization of communication: Handbooks of communication science (Vol. 21, pp. 273-296). Berlin: Mouton de Gruyter.

Jansson, A. (2015a). The molding of mediatization: The stratified indispensability of media in close relationships. Communications: The European Journal of Communication Research, 40(4), 379-401.

Jansson, A. (2015b). Using Bourdieu in critical mediatization research: Communicational doxa and osmotic pressures in the field of UN organizations. MedieKultur, 58, 13-29.

Jansson, A. (2018). Mediatization and mobile lives: A critical approach. London: Routledge.

Jensen, K. B. (2013). Definitive and sensitizing conceptualizations of mediatization. Communication Theory, 23(3), 203-222.

Kaplan, S. J. (1990). Visual metaphors in the representation of communication technology. Critical Studies in Media Communication, 7(1), 37-47.

Klausen, M., \& Møller, K. (2018). Unimaginable homes: Negotiating ageism through media use. In K. Fast, A. Jansson, J. Lindell, L. R. Bengtsson, \& M. Tesfahuney (Eds.), Geomedia studies: Spaces and mobilities in mediatized worlds (pp. 152-170). London: Routledge. 
Krotz, F. (2009). Mediatization: A concept with which to grasp media and societal change. In K. Lundby (Ed.), Mediatization: Concept, changes, consequences (pp. 21-40). New York, NY: Lang.

Krotz, F. (2017). Explaining the mediatization approach. Javnost-The Public, 24(2), 103-118.

Latour, B. (2005). Reassembling the social: An introduction to actor-network-theory. Oxford: Oxford University Press.

Lefebvre, H. (1991). The production of space (Vol. 142, D. Nicholson-Smith, Trans.). Oxford: Blackwell.

Lundby, K. (Ed.). (2009). Mediatization: Concept, changes, consequences. New York, NY: Peter Lang.

Mackay, H., \& Gillespie, G. (1992). Extending the social shaping of technology approach: Ideology and appropriation. Social Studies of Science, 22(4), 685-716.

Marvin, C. (1988). When old technologies were new: Thinking about electric communication in the late nineteenth century. Oxford: Oxford University Press.

McLuhan, M. (1964). Understanding media: The extensions of man. New York, NY: McGraw-Hill.

Meyrowitz, J. (1986). No sense of place: The impact of electronic media on social behavior. Oxford: Oxford University Press.

Miller, T. (2016). Cybertarian flexibility-When prosumers join the cognitariat, all that is scholarship melts into air. In M. Curtin \& K. Sanson (Eds.), Precarious creativity: global media, local labor (pp. 19-32). Oakland, CA: University of California Press.

Morley, D. (2009): For a materialist, non-media-centric media studies. Television \& New Media, 10(1), 114-116.

Mosco, V. (2004). The digital sublime: Myth, power, and cyberspace. Cambridge, MA: MIT Press.

Nye, J. S. (2002). The information revolution and American soft power. Asia Pacific Review, 9(1), 60-76.

O'Flynn, G., \& Petersen, E. B. (2007). The 'good life' and the 'rich portfolio': Young women, schooling and neoliberal subjectification. British Journal of Sociology of Education, 28(4), 459-472.

Pinch, T. J., \& Bijker, W. E. (1984). The social construction of facts and artefacts: Or how the sociology of science and the sociology of technology might benefit each other. Social Studies of Science, 14(3), 399-441.

Polson, E. (2016). Privileged mobilities: Professional migration, geo-social media, and a new global middle class. New York, NY: Peter Lang.

Poster, M. (2008). Global media and culture. New Literary History, 39(3), 685-703.

Ragnedda, M., \& Muschert, G. W. (Eds.). (2013). The digital divide: The Internet and social inequality in international perspective (Vol. 73). London: Routledge.

Robins, K., \& Webster, F. (1999). Times of the technoculture: From the information society to the virtual life. London: Routledge.

Rose, G. (2018). Look inside ${ }^{\mathrm{TM}}$ : Corporate visions of the smart city. In K. Fast, A. Jansson, J. Lindell, L. R. Bengtsson, \& M. Tesfahuney (Eds.), Geomedia studies: Spaces and mobilities in mediatized worlds (pp. 97-113). London: Routledge.

Russell, S. (1986). The social construction of artefacts: A response to Pinch and Bijker. Social Studies of Science, 16(2), 331-346.

Schulz, W. (2004). Reconstructing mediatization as an analytical concept. European Journal of Communication, 19(1), 87-101.

Schutz, A. (1967). The phenomenology of the social world. Evanston, IL: Northwestern University Press.

Telenor. (2017). Workfulness: En handbok för företag som vill skapa en sund digital arbetsmiljö [Workfulness: A handbook for companies aiming for a healthy digital work environment]. Retrieved from https:// www.telenor.se/globalassets/mediabibliotek/telenor -foretag/pdfer/workfulness/workfulness_handbok_ telenor.pdf

Terranova, T. (2000). Free labor: Producing culture for the digital economy. Social Text, 18(2), 33-58.

Tesfahuney, M., \& Schough, K. (Eds.). (2016). Privileged mobilities: Tourism as world ordering. Newcastle upon Tyne: Cambridge Scholars Publishing.

Tinker, T., \& Neimark, M. (1987). The role of annual reports in gender and class contradictions at General Motors: 1917-1976. Accounting, Organizations and Society, 12(1), 71-88.

Tomlinson, J. (2008) 'Your life to go': The cultural impact of new media technologies. In A. Hepp, F. Krotz, \& S. Moores (Eds.), Connectivity, networks and flows: Conceptualizing contemporary communications (pp. 59-68). Cresskill, NJ: Hampton Press, Inc.

Williams, R. (1974). Television and cultural form. London: Fontana/Collins.

\section{About the Author}

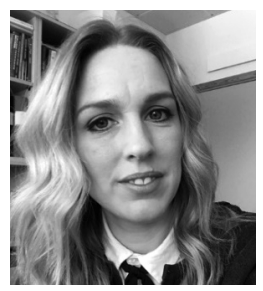

Karin Fast (PhD) is Senior Lecturer in Media and Communication Studies and part of the Geomedia Research Group at Karlstad University, Sweden. Her research interests include (geo-)mediatisation, media work, transmediality, and cultural industries. She has previously published in journals such as Journal of Computer-Mediated Communication, International Journal of Cultural Studies, European Journal of Cultural Studies, Media Culture and Society and Communication Theory. 